\title{
The Role of Anatase Nanoparticles on the Mechanical Properties and the Bacterial Adhesion to Acrylonitrile-Butadiene-Styrene Terpolymer
}

\author{
Imad Ali Disher Al-Hydary ${ }^{a} \mathbb{0}^{-}$, Muna Sabbar Jebar Al-Rubia $e^{b}$ \\ ${ }^{a}$ Department of Ceramics and Building Materials, College of Materials Engineering, University of \\ Babylon, Iraq \\ ${ }^{b}$ Department of medical analysis, Babylon Technical Institute, Al-Furat Al-Awsat Technical University, \\ Babylon, Iraq
}

Received: April 28, 2018; Revised: October 05, 2018; Accepted: November 14, 2018

This work aims to synthesize composite material which combines adequate mechanical properties and high resistance to bacterial adhesion. Such materials are needed in many components in the medical, industrial, and environmental applications. To obtain that combination, high weight percents of anatase nanoparticles, as bacterial adhesion reducer, were incorporated into a matrix of the ABS terpolymer. Pseudomonas aeruginosa, Staphylococcus aureus, and Klebsiella pneumonia were selected for the bacterial adhesion tests. The surface properties of the composites were investigated and correlated to the adhesion behavior using nonlinear regression technique. It has been found that adding anatase nanoparticles improves the stiffness and the compressive strength of the terpolymer with a noticeable reduction in the flexural strength due to the development of minor defects in the structure. Nevertheless, a composite containing $10 \mathrm{wt} \%$ of anatase nanoparticles exhibited an interesting and adequate combination of the mechanical properties and the resistance to bacterial adhesion. The regression analysis produced a mathematical formula that excellently fits the experimental data. Such formula can be used to predict the bacterial adhesion to a surface based on its multi-scale features.

Keywords: Anatase, Bacterial Adhesion, ABS Terpolymer, Polymer Composites, Nanoparticles.

\section{Introduction}

For many decades, the adhesion of bacteria to the surface of solids attracted extensive interest from many researchers; this is due to its great impact in the environmental, medical and industrial applications. Beside the importance of the bacterial adhesion for many beneficial microbial communities, the bacterial adhesion is the first step for the colonization of pathogenic bacteria that cause many diseases and fouling in many environments and industries. Thus, reduction the adhesion of the pathogenic bacteria to the surfaces of the materials is a very important issue because the bacterial adherence to surfaces is the critical first step in biofilm formation which, upon forming, makes the surface of the material a source for the spreading of the infection by the pathogenic bacteria ${ }^{1-3}$.

In order to prevent, or reduce, the adhesion of the undesired bacteria and its subsequent biofilm formation, different strategies have been developed. These typically include the use of biocides, antibacterial metallic ions $s^{4-6}$, highly reactive species produced by the photocatalysts ${ }^{2,7}$, and recently the use of superhydrophobic surfaces ${ }^{8-10}$. However, it has been reported that the use of biocides may increase the bacterial resistance and cross-resistance to antibiotics ${ }^{9,11,12}$. Also, the use of metallic ions such as $\mathrm{Ag}^{+}$may have potential implications for human health and environment ${ }^{7,13,14}$. Based

"e-mail: imdali4@uobabylon.edu.iq. on that, incorporating the surface with photocatalysts and/or superhydrophobic particles became an important research area in the last few years ${ }^{9}$. However, understanding the phenomena associated with the bacterial adhesions to these surfaces and their inhibitions are still under development ${ }^{15-18}$.

It is well reported that anatase has a photocatalytic activity higher than that of rutile ${ }^{14,19-21}$, thus; it has higher ability to produce different reactive species, such as hydroxyl radical, hydrogen peroxide and superoxide, in different environments. Moreover, anatase nanoparticles have been reported to have superhydrophobic characteristics, thus; anatase nanoparticles and nanostructures attracted considerable interest in reducing the bacterial adhesion to surfaces ${ }^{20,22}$. However, challenges still remain in applying nanoparticles in real applications because of the fragile micro/nano structure and the fast degradation of surface chemistry. While many routes are still in early development stages, the use of composite materials is the most mature route for facilitating nanoparticles durably for inhibition bacterial adhesion ${ }^{1,9,23}$. However, while the high percent of nanoparticles in the composites is essential for the reduction of the bacterial adhesion, it results in serious decline in the mechanical properties. This is mainly due to the agglomeration of the nanoparticles and the formation of voids in the composites ${ }^{24}$.

In our previous works, phase pure anatase nanoparticles were prepared and incorporated in a matrix of acrylonitrilebutadiene-styrene terpolymer (ABS) with high weight percents ${ }^{25}$. The bacterial adhesion test gave evidence that these 
composites have the ability to reduce the bacterial adhesion noticeably. In the current work, the effect of the high weight percents of the anatase nanoparticles on the mechanical properties of $\mathrm{TiO}_{2} / \mathrm{ABS}$ composites was investigated. The combination of adequate mechanical properties and the resistance to bacterial adhesion is required for many potential applications including the devices, tools, and furniture in the medical, industrial, and environmental fields.

Besides the efforts to reduce the bacterial adhesion to solids, many research works have been reported to correlate the adhesion of the bacteria to the surface properties of the bacteria as well as the substratum using different approaches ${ }^{16,26-28}$. Correlating the material properties to the adhering bacteria is very important because the mechanisms underlying the adhesion of bacteria to the surface are still unclear $^{29-31}$. However, the improper selection of the variables and the regression technique led to poor agreement between the model and the experimental data. This indicates that better models are still needed. For example, many studies included the surface free energy, polarity of the surface, and the work of adhesion as independent variables in their model, although these are dependant variables of the contact angle which is already included in the model as independent variable $16,26,32-34$.

In the current work the nonlinear regression technique was adopted, for the first time as per our best knowledge, to correlate the number of adhering bacteria to the surface properties of the composites. The number of adhering bacteria was selected as dependant variable, while, the contact angle, nanoscale roughness, and the microscale roughness were selected as independent variables because the surface roughness and the hydrophobicity are the main factors influencing microbial adhesion ${ }^{9,35}$.

\section{Experimental Work}

Acrylonitrile Butadiene Styrene (CHIMEI, PA-717C, China) and acetone (Sigma-Aldrich, NLT $99.5 \%$ ) were used as received without further treatments. $\mathrm{TiO}_{2}$ phase pure anatase nanoparticles, with particle size in the range of $30-70 \mathrm{~nm}$ and BET surface area of $38 \mathrm{~m}^{2} / \mathrm{g}$, were prepared as described in our previous work ${ }^{36}$.

$\mathrm{TiO}_{2} / \mathrm{ABS}$ composites with different $\mathrm{TiO}_{2}$ weight percents of $1,5,10,20$ and 35 were prepared by mixing a solution of ABS terpolymer in acetone with a suspension of $\mathrm{TiO}_{2}$ nanoparticles in acetone. The polymer solution was prepared by dissolving the $\mathrm{ABS}$ terpolymer at $50^{\circ} \mathrm{C}$, under magnetic stirring, in acetone with a ratio of $1 \mathrm{~g}$ of the polymer per $7 \mathrm{ml}$ of acetone. While, the suspension was prepared by mixing the $\mathrm{TiO}_{2}$ nanoparticles with acetone using sonication treatment for $2 \mathrm{~h}$ at room temperature with a ratio of $1 \mathrm{~g}$ of $\mathrm{TiO}_{2}$ nanoparticles per $20 \mathrm{ml}$ of acetone. The suspension was added to the solution and the mixture was aged under magnetically stirring overnight at room temperature to consolidate the dispersion of the $\mathrm{TiO}_{2}$ nanoparticles in the ABS solution. After aging, distilled water was added drop by drop to the mixture with continuous stirring to get a paste like material. The paste was oven-dried at $80^{\circ} \mathrm{C}$ for $24 \mathrm{~h}$ and crashed using mortar and pestle to form granules.

Pellets were made by hot pressing method using a steel die and hydraulic press with controlled heating unit. The applied pressure was $11 \mathrm{MPa}$ and the heating rate was $2^{\circ} \mathrm{C} /$ min. After heating up to $165^{\circ} \mathrm{C}$, the specimens were cooled to room temperature. The specimens were cut to the desired dimensions and subjected to ordinary surface grinding process using SiC-paper, from 600 to 1200 grit, and were polished using alumina powder with average particle size of $1,0.3$, and $0.05 \mu \mathrm{m}$.

FTIR test was performed for the $\mathrm{TiO}_{2}$ nanoparticles and ABS terpolymer as well as their composites to study the bonding between the ABS matrix and the anatase nanoparticles. The FTIR spectra were recorded using (Shimadzu 1800, Japan) over wavenumber range of $400-4000 \mathrm{~cm}^{-1}$ with resolution of $2 \mathrm{~cm}^{-1}$.

As the comparison between the measured and estimated density can give an idea about the defects in the microstructure, the density of the specimens was measured using Mettler Toledo (AG204, Switzland) densitometer and the theoretical density was estimated using the rule of mixtures ${ }^{37}$.

The ultimate-point compressive and flexural strengths were measured for specimens with dimensions of $(3.5 \mathrm{~mm}$ x $12.7 \mathrm{~mm}$ x $16 \mathrm{~mm}$ ) and (2 $\mathrm{mm} \mathrm{x} 12.7 \mathrm{~mm} \mathrm{x} 60 \mathrm{~mm}$ ) respectively. Universal test machine (Instron 5500R, USA) with a $150 \mathrm{kN}$ load cell at a crosshead speed of $0.5 \mathrm{~mm} /$ min was used to perform the tests. The R scale Rockwell hardness (RHR) was tested using digital hardness testers (TRSD M/P, India).

The contact angle test was carried out using automated contact angle instrument (SL200K series, KINO). The sessile drop technique was followed using deionized water at $25^{\circ} \mathrm{C}$. For triplicate samples, $3 \mu \mathrm{L}$ droplet was automatically dropped on the surface and the measurement was achieved within 15 $\mathrm{s}$ after the positioning of the drop. The surface free energy (SFE) was calculated based on the average contact angle data using the Neumann's standard formula.

The microscale surface roughness was measured at three different sites with a stylus instrument (SRT-6210) for three specimens of each composite. The microroughness values were given as arithmetic average peak-to-valley value ( $\mu \mathrm{Ra})$.

Three-dimensional images of the surface topography were obtained using the tapping mode scan by means of scan probe microscope machine (SPM-AA3000, Angstrom Advanced, USA), this method was also used to determine the surface nanoroughness at randomly selected areas of $(2 \mu \mathrm{m} \times 2 \mu \mathrm{m})$ of each specimen.

The culture of Pseudomonas aeruginosa (PA), Staphylococcus aureus (SA) and Klebsiella pneumonia $(K P)$ bacterial species and their adhesion to the sterilized 
specimens were performed as described in our previous work given in details elsewhere ${ }^{25}$.

Minitab software (17.3.1) was used to analyze the obtained data and to perform the nonlinear regression; also, OriginPro 2016 software (b9.3.266) was used to represent the results graphically.

\section{Results and Discussion}

Fig. 1 shows the FTIR spectra of ABS terpolymer, anatase nanoparticles, and $\mathrm{TiO}_{2} / \mathrm{ABS}$ composite. For the ABS terpolymer, the bands at 968,1490 , and $2237 \mathrm{~cm}^{-1}$ are the characteristic bands of butadiene, styrene, and acrylonitrile respectively. The bands at 3060, 1607, 1508, 1457, and $830 \mathrm{~cm}^{-1}$ belong to the benzene ring, the band at $2250 \mathrm{~cm}^{-1}$ is attributed to $\left({ }^{\mathrm{V}}-\mathrm{C} \equiv \mathrm{N}\right)$ bond, the band at $1647 \mathrm{~cm}^{-1}$ is for $\left({ }^{\mathrm{v}}>\mathrm{C}=\mathrm{C}<\right.$ ), the bands at 965 and $740 \mathrm{~cm}^{-1}$ are due to $(\omega=\mathrm{CH})$, and the band at $1700 \mathrm{~cm}^{-1}$ is assigned to $(\mathrm{C}=\mathrm{O})^{38-40}$.

The absorptions due to the vibration modes representing the anatase structure have been noticed; two bands assigned to Ti-O vibration have been noticed, the first at $500-800 \mathrm{~cm}^{-1}$ and the second at $1033 \mathrm{~cm}^{-141,42}$. The comparison of the FTIR spectrum of the anatase/ABS composites that contains 5 and $20 \mathrm{wt} \%$ anatase nanoparticles, which have been chosen as representative spectra for the composites since all of them have mainly the same spectrum, with the spectrum of ABS and anatase nanoparticles showed that the ABS band at 965 and $740 \mathrm{~cm}^{-1}$ were disappeared and most of the ABS bands were subjected to shifting and variation in the intensities in the spectrum of the composites. The anatase band at 1033 $\mathrm{cm}^{-1}$ was shifted to $1028 \mathrm{~cm}^{-1}$, while new bands at 1049 and $3026 \mathrm{~cm}^{-1}$ have been observed in the spectrum of the composites. The disappearance of the band, shifting of some bands, and development of new absorption bands indicate the interaction between the anatase nanoparticles and the ABS groups. This interaction is very important to improve

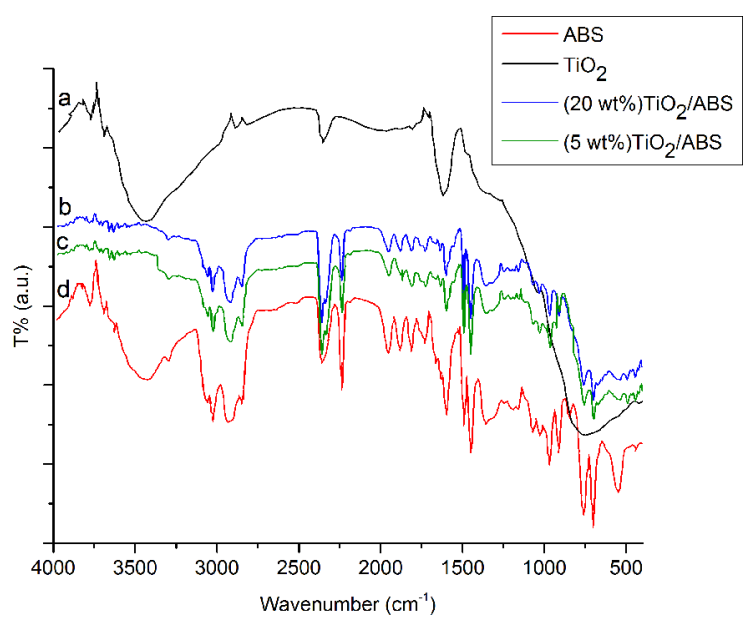

Figure 1. FTIR spectra of a) Anatase nanoparticles, b) $\mathrm{TiO}_{2}(20 \mathrm{wt}$ $\%$ )/ABS composite, c) $\mathrm{TiO}_{2}(5 \mathrm{wt} \%$ )/ABS composite and d) ABS terpolymer the mechanical properties of the composites through the reinforcement effect.

A comparison between the experimentally measured density of the anatase/ABS composites and the theoretical density, which was calculated according to the rule of mixtures, is given in Fig. 2. It is obvious that the experimental density have an excellent matching with the theoretical density of the composites. However, minor deviation can be noticed when the percent of anatase nanoparticles exceeds $10 \mathrm{wt} \%$. This indicates the development of minor defects in the structure of the composites. These defects may be developed because of the agglomeration of the anatase nanoparticles. These defects may work, based on their size, shape and distribution, as centres for the stress concentration that, in turn, reduces the mechanical strength of the composites.

Fig. 3 shows the profiles of the Rockwell's hardness of the prepared composites. It is clearly appeared that the hardness of the samples decreases with the increment of $\mathrm{TiO}_{2}$ percentage. This may be due to the agglomeration of $\mathrm{TiO}_{2}$ nanoparticles which can be detected by the relatively big indenter in Rockwell hardness test $(1 / 2$ " ball). However, the

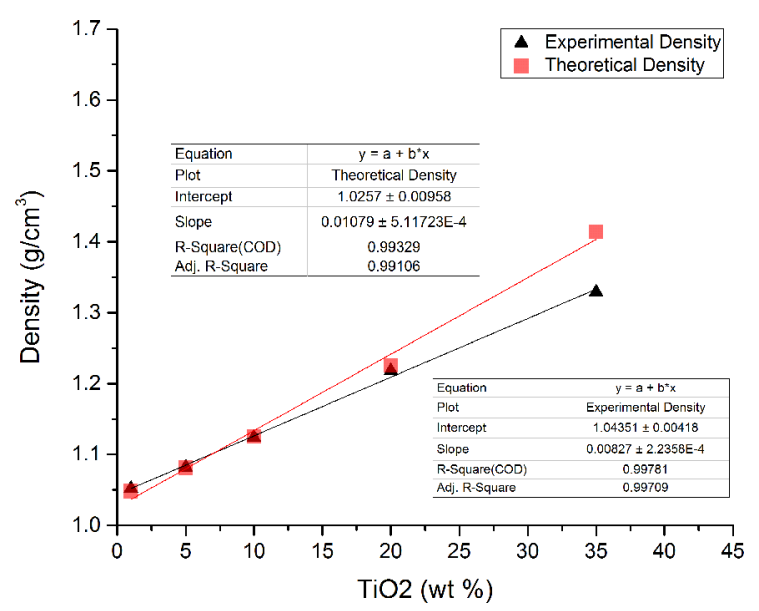

Figure 2. The experimental and the theoretical density of the $\mathrm{TiO}_{2} /$ ABS composites

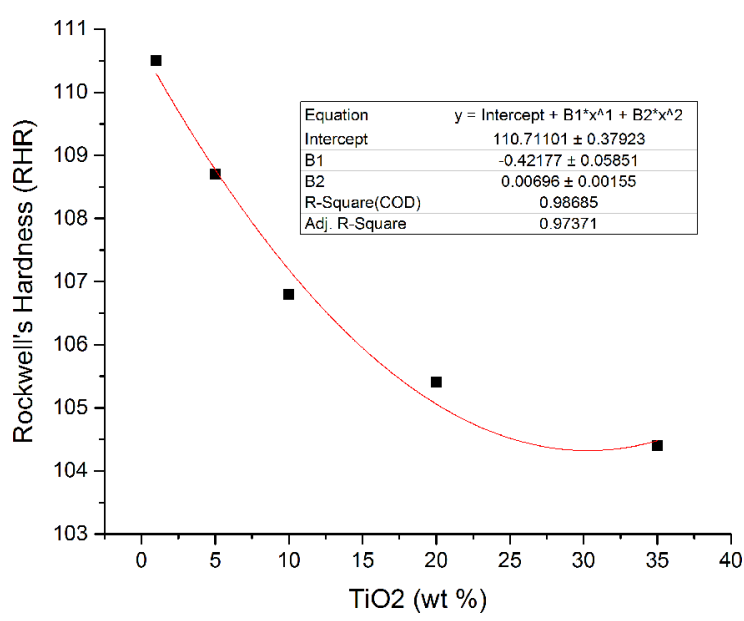

Figure 3. Rockwell's hardness of the $\mathrm{TiO}_{2} / \mathrm{ABS}$ composites 
maximum reduction in the hardness doesn't exceed $5 \%$ of the hardness of the ABS polymer indicating that the composites almost maintain the hardness of the ABS engineering polymer which is necessary for different applications.

Fig. 4 shows the change in compressive strength of the $\mathrm{TiO}_{2} / \mathrm{ABS}$ composites based on the variation of weight percent of $\mathrm{TiO}_{2}$. The compressive strength increases with increment of $\mathrm{TiO}_{2}$ percentage, up to $10 \mathrm{wt} \%$, because of the reinforcement effect of the $\mathrm{TiO}_{2}$, this shows an advantage for the technique followed here to prepare the composite over the traditional melting or solution casting techniques; as it has been reported that one of the challenges in the preparation of polymer matrix composites is the ability to increase the level of nano reinforcement which is not only important for mechanical properties but also for the other properties ${ }^{24}$. However, when the percentage of $\mathrm{TiO}_{2}$ exceeds $10 \mathrm{wt} \%$, the profile of the compressive strength follows decelerating slop may be due to the minor defects in the composites. As shown in Fig. 5, these defects seem to dominate the mechanical behavior of the composites in the case of flexural strength which is, as compared to compressive strength, very sensitive to the defects in the material.

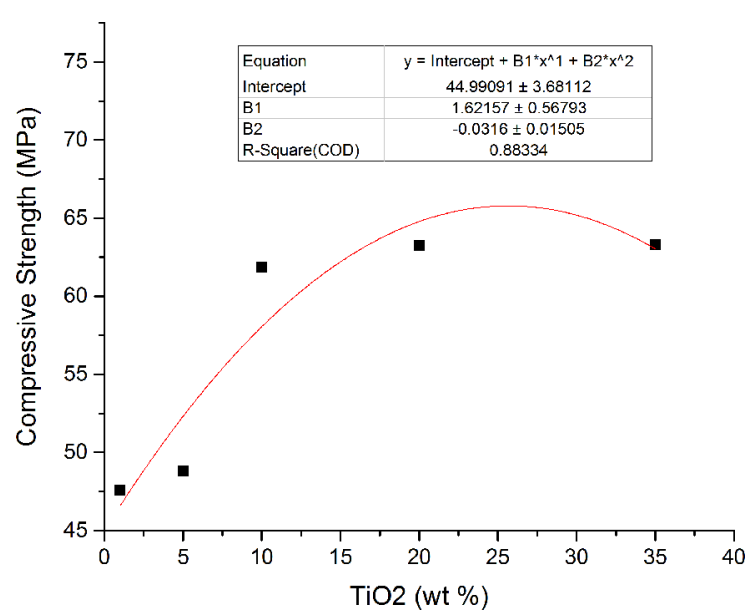

Figure 4. The compressive strength of the $\mathrm{TiO}_{2} / \mathrm{ABS}$ composites

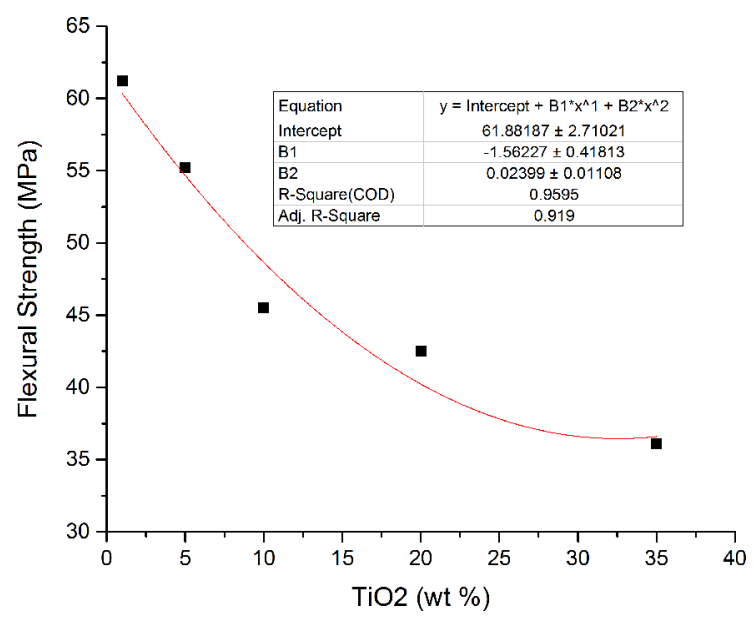

Figure 5. The flexural strength of the $\mathrm{TiO}_{2} / \mathrm{ABS}$ composites
Fig. 6 and Fig.7show the compressive and flexural modulus of elasticity of the $\mathrm{TiO}_{2} / \mathrm{ABS}$ composites. It has been noticed that the modulus's of the samples increase with increasing the $\mathrm{TiO}_{2}$ percent indicating the enhancement of the stiffness of the composites. This improvement is due to hindering the movement of the polymer chains as a result of the reinforcement role of $\mathrm{TiO}_{2}$. Such improvement is important not only from the mechanical point of view as it increases the rigidity of the materials but also it may positively affect the bacterial adhesion resistance of the materials as it has been reported, in many studies, that the materials with high stiffness are more likely to resist the bacterial adhesion ${ }^{3,10,30}$.

The contact angles of the prepared composites are demonstrated in Fig. 8. It can be seen, as illustrated in Fig. 9, the contact angle increases when the $\mathrm{TiO}_{2}$ weight percent increases, this is expected because of the high hydrophobicity of the anatase nanoparticles. It is important to note that the surface of the composite becomes hydrophobic, with contact angle higher than $90^{\circ}$, when the amount of $\mathrm{TiO}_{2}$ exceeds $5 \mathrm{wt} \%$. The surface free energy (SFE) of the

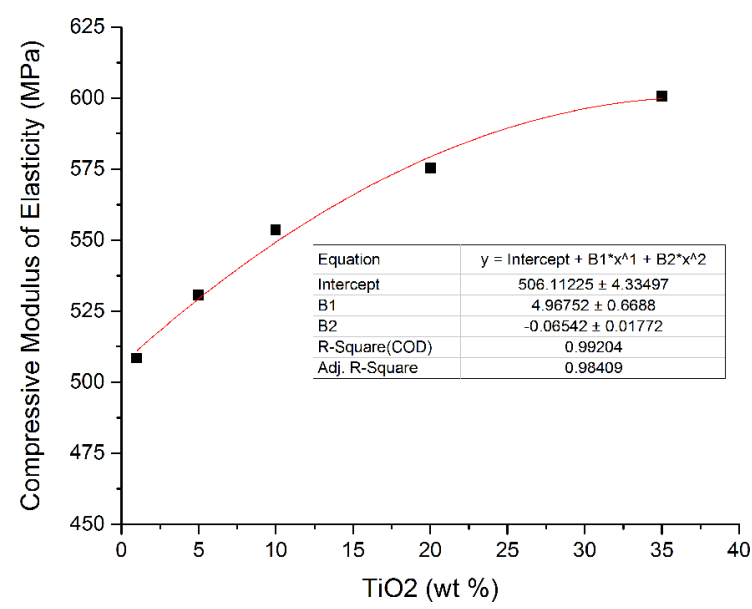

Figure 6. The compressive modulus of elasticity of the $\mathrm{TiO}_{2} / \mathrm{ABS}$ composites

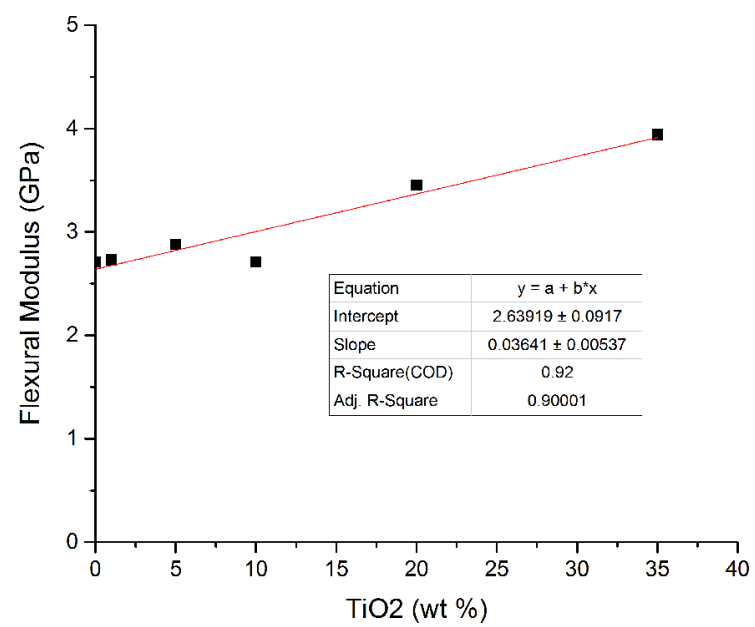

Figure 7. The flexural modulus of elasticity of the $\mathrm{TiO}_{2} / \mathrm{ABS}$ composites 
composites is given in Fig. 10, the results showed that the SFE is reduced along with the increment of the $\mathrm{TiO}_{2}$ weight percent; this indicates the weak interaction between the water and the hydrophobic surface of the composite.

The 3D images of the surface of the composites, obtained from AFM, are shown in Fig. 11. It is obvious that the nanoscale topographical features of the surface become finer and shallower upon the addition of anatase nanoparticles. This explains, in addition to the weak chemical interaction, the hydrophobicity of the surface as these features work on trapping air bubbles and reduce the contact with water. However, these topographical features become coarser and deeper when the $\mathrm{TiO}_{2}$ exceeds $20 \mathrm{wt} \%$, this is may be related to the change in the machineability of the composites as well as the presences of the defects caused by the agglomeration of the anatase nanoparticles.

As shown in Table 1, the nanoscale roughness (nRa), which is a direct result of the nanoscale topographical features, is found to be reduced upon the addition of the anatase nanoparticles up to $20 \mathrm{wt} \%$. Besides, a fluctuating

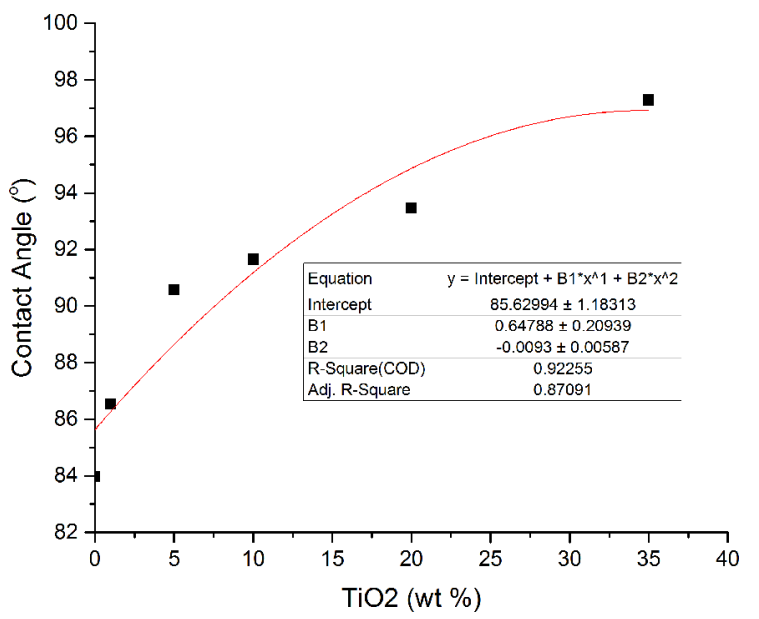

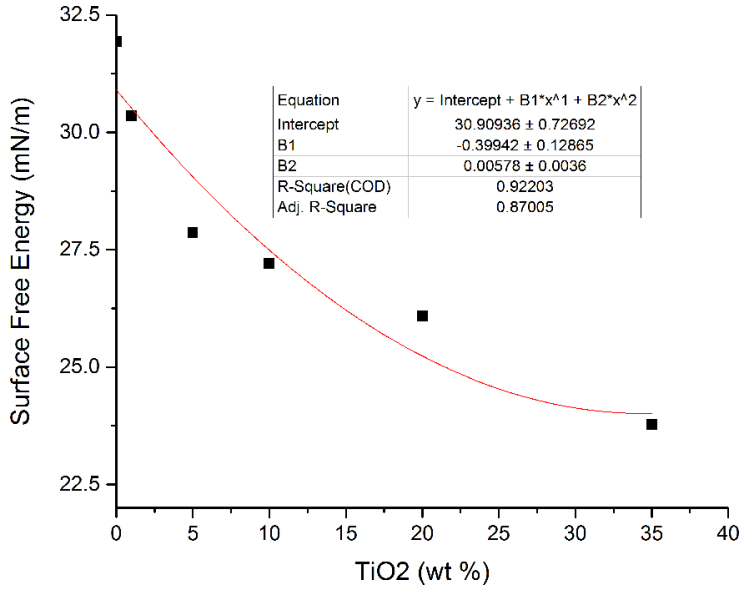

Figure 10. The surface free energy (SFE) of the $\mathrm{TiO}_{2} / \mathrm{ABS}$ composites

microscale roughness ( $\mu \mathrm{Ra})$ is obtained indicating the variation in the machineability of the composites.

Table 2 shows the results of the bacterial adhesion to the surface of the $\mathrm{TiO}_{2} / \mathrm{ABS}$ composites. It can be seen that the number of adhering bacteria, for all the selected species is reduced when the $\mathrm{TiO}_{2}$ nanoparticles is incorporated in the ABS terpolymer. However, there isn't a linear relationship between the numbers of adhering bacteria and the selected independent variables neither as single variable nor as multivariable. Based on that, the nonlinear regression technique was used to correlate the results using Minitab software (17.3.1). It has been found that the equations which can be used to represent the obtained results of the bacterial adhesion for all the selected species have a common form shown in equation (1).

$$
\begin{aligned}
D= & C_{1}+C_{2} X_{1}+C_{3} X_{2}+C_{4} X_{1} X_{2}+ \\
& C_{5} X_{1} X_{3}+C_{6} X_{2} X_{3}
\end{aligned}
$$

Figure 8. The contact angles of the $\mathrm{TiO}_{2} / \mathrm{ABS}$ composites

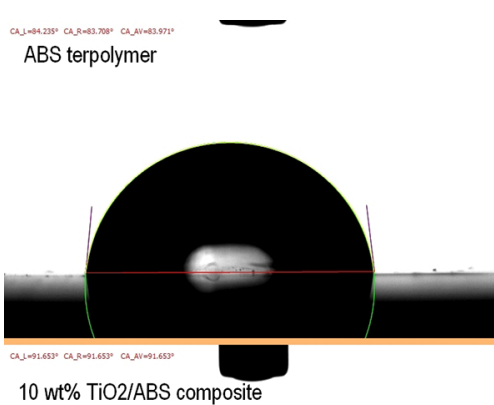

10 wt $\%$ TiO2/ABS composite

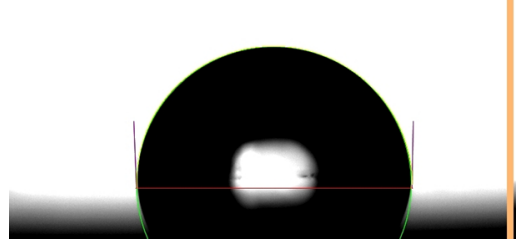

5 wt $\%$ TiO2/ABS composite

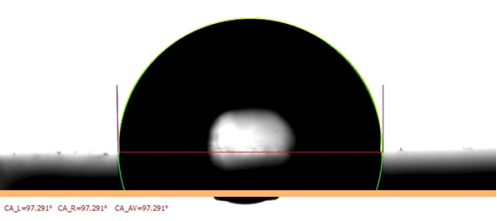

$35 \mathrm{wt} \%$ TiO2/ABS composite

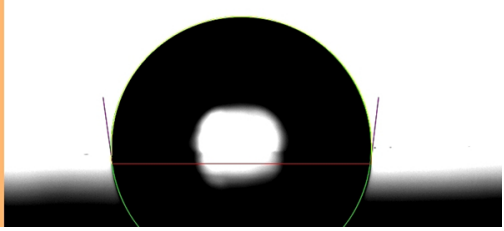

Figure 9. The images of the sessile water drop on the surface of $\mathrm{TiO}_{2} / \mathrm{ABS}$ composites 


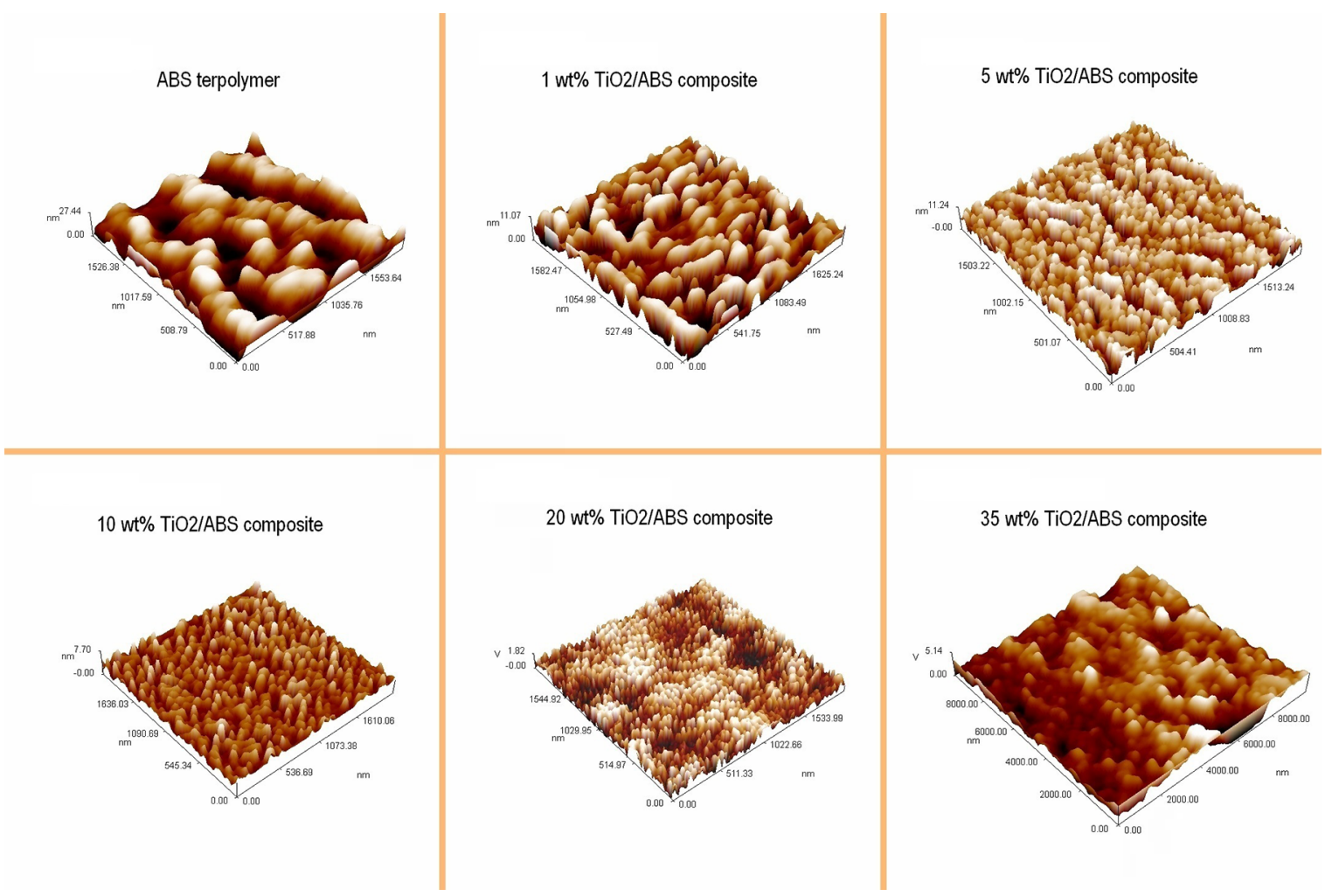

Figure 11. The 3D nanoscale topographical images of surface of $\mathrm{TiO}_{2} / \mathrm{ABS}$ composites

Table 1. Values of the contact angle, nanoroughness, and microroughness of the $\mathrm{TiO}_{2} / \mathrm{ABS}$ composites

\begin{tabular}{cccc}
\hline $\begin{array}{c}\mathbf{T i O}_{2} \\
(\mathbf{w t} \%)\end{array}$ & $\begin{array}{c}\text { Contact } \\
\text { Angle }\left({ }^{\circ}\right)\end{array}$ & $\begin{array}{c}\text { Nanoroughness } \\
\text { nRa }(\mathbf{n m})\end{array}$ & $\begin{array}{c}\text { Microroughness } \\
\boldsymbol{\mu R a}(\boldsymbol{\mu m})\end{array}$ \\
\hline 0 & 83.97 & 6.86 & 2.1 \\
1 & 86.53 & 2.77 & 2.58 \\
5 & 90.57 & 2.08 & 1.18 \\
10 & 91.65 & 1.02 & 1.9 \\
20 & 93.47 & 0.449 & 2.62 \\
35 & 97.29 & 1.1 & 3 \\
\hline
\end{tabular}

Table 2. Number of adhering bacteria on the $\mathrm{TiO}_{2} / \mathrm{ABS}$ composites

\begin{tabular}{|c|c|c|c|}
\hline \multirow[b]{2}{*}{$\begin{array}{l}\mathrm{TiO}_{2} \\
\left(\mathrm{wt}^{2} \%\right)\end{array}$} & \multicolumn{3}{|c|}{ Number of Adhering Bacteria } \\
\hline & $\begin{array}{l}\text { Staphylococcus } \\
\text { aureus (SA) }\end{array}$ & $\begin{array}{c}\text { Pseudomonas } \\
\text { aeruginosa } \\
\text { (PA) }\end{array}$ & $\begin{array}{c}\text { Klebsiella } \\
\text { pneumonia } \\
\text { (KP) }\end{array}$ \\
\hline $\mathbf{0}$ & 150339 & 1401176 & 40460 \\
\hline 1 & 111688 & 773543 & 7487 \\
\hline 5 & 105283 & 558955 & 7389 \\
\hline 10 & 60388 & 548980 & 4026 \\
\hline 20 & 94110 & 653234 & 10592 \\
\hline 35 & 82651 & 688757 & 4369 \\
\hline
\end{tabular}

Where $D$ is the number of adhering bacteria, $X_{1}$ is the contact angle, $X_{2}$ is the nanoscale roughness (nRa), $X_{3}$ is the microscale roughness ( $\mu \mathrm{Ra}$ ), and $C_{i}$ are the coefficients of the equation which depend on the type of the species and find the relative importance of the variables in the adhering process. The values of these coefficients are given in Table 3 along with the values of the coefficient of the goodness of fitting $\left(\mathrm{R}^{2}\right)$.

Fig. 12 demonstrates the adhering behavior of the selected bacterial species as a function of the selected independent variables in the form of ternary contour graph which is used for the first time, for this purpose, in the current study. The ternary contour graphs were plotted using OriginPro 2016 software (b9.3.266), the values of the independent variables were generated using a programming code, written via quick basic programming language, in such a way that the sum of the three independent variables is always equal to one, while, the values of the dependant variable, the number of the adhering bacteria, was calculated according to equation (1) using the set of the coefficients concerning each type of bacteria. The obtained formula, with the help of the contour graphs, can be used not only to predict the adhesion of a given bacterial species to the surface of a specific material but also it helps to understand the combined effect of the three variable on the bacterial adhesion.

It can be seen that Pseudomonas aeruginosa (PA) and Staphylococcus aureus (SA) prefer a surface with low to moderate contact angle, i.e. hydrophilic surface, as these species have a hydrophilic surfaces ${ }^{43,44}$ that can be attached largely to hydrophilic surfaces ${ }^{1,45}$. While, Klebsiella pneumonia 
(KP), which has hydrophilic surface ${ }^{46}$, prefers a surface with very specific range of moderate contact angle.

On the other hand, it has been found that moderate to high nanoscale roughness is preferable for the adhesion of bacteria, this confirms that the low nanoscale topographical features, which trap air bubbles that form a barrier between the bacteria and the solid surface, prevent the bacteria to cross the air-water interface as reported in recent studies ${ }^{9,47}$.

Staphylococcus aureus (SA) seems to be neutral regarding the microscale roughness, this is may be due to its small size and spherical shape that help its anchor to the surface features ${ }^{47}$, while Pseudomonas aeruginosa (PA) prefer high microscale roughness which is compatible with its larger size, and Klebsiella pneumonia (KP) prefers low microscale and high nanoscale roughness's in agreement with the findings of recent report ${ }^{48}$.

Fig. 13 shows a comparison among the adhesion of the selected species to the surface of the $\mathrm{TiO}_{2} / \mathrm{ABS}$ composites using a common axis for the dependent variable. It is clear that the tendencies of the species to adhere to the surface follow the sequence Klebsiella pneumonia $<$ Staphylococcus aureus $<$ Pseudomonas aeruginosa. These results are in agreement with that reported in literatures ${ }^{8,49-51}$ indicating the validity of the obtained model and the potential of the ternary contour graph to represent this kind of results.

\section{Conclusions}

The addition of anatase nanoparticles to the ABS terpolymer alters the surface properties of the polymer dramatically in the microscale as well as the nanoscale. The adhesion of Klebsiella pneumonia, Staphylococcus aureus, and Pseudomonas aeruginosa species to the surface of the prepared $\mathrm{TiO}_{2} / \mathrm{ABS}$ composites can be reduced significantly by obtaining a surface with high contact angle and low nanoscale roughness; this can be achieved using high weight percents of the anatase nanoparticles. However, the compromising between the mechanical properties and the bacterial adhesion is required when the flexural strength is needed. In such case, a composite containing $10 \mathrm{wt} \%$ of anatase nanoparticles can be used as it shows the best combination between the mechanical properties and high resistance to bacterial adhesion. Such materials can be used for medical

Table 3. Values of the $\mathrm{C}_{\mathrm{i}}$ coefficients for the formula of Staphylococcus aureus (SA), Pseudomonas aeruginosa (PA), and Klebsiella pneumonia $(\mathrm{KP})$

\begin{tabular}{cccccccc}
\hline $\begin{array}{c}\text { Type of } \\
\text { bacteria }\end{array}$ & $\boldsymbol{C}_{I}$ & $\boldsymbol{C}_{2}$ & $\boldsymbol{C}_{3}$ & $\boldsymbol{C}_{4}$ & $\boldsymbol{C}_{5}$ & $\boldsymbol{C}_{6}$ & $\mathrm{R}^{2}$ \\
\hline SA & 92943 & -57864 & 36748 & 17978 & 8675 & 122433 & 1 \\
PA & 339073 & -896274 & -296513 & -724730 & 405164 & 594356 & 1 \\
KP & 24095 & -1754 & 18793 & -37991 & -4422 & -35368 & 1 \\
\hline
\end{tabular}
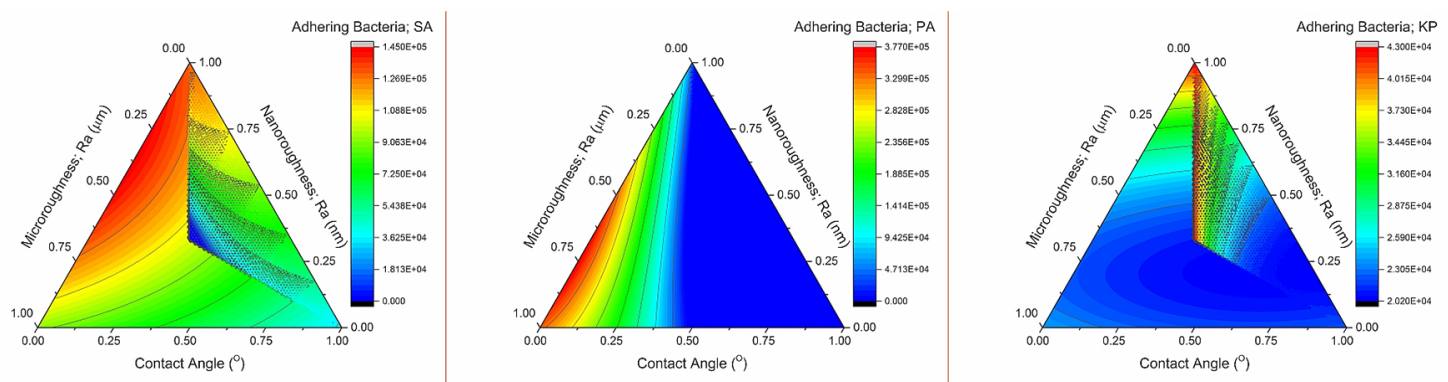

Figure 12. The adhering behavior of the Staphylococcus aureus (SA), Pseudomonas aeruginosa (PA), and Klebsiella pneumonia (KP)
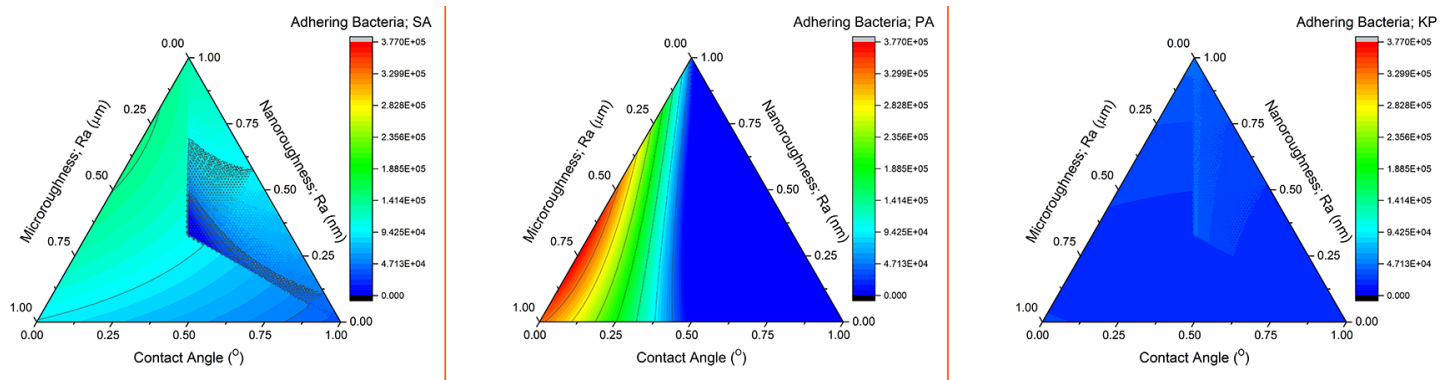

Figure 13. A comparison among the adhesion of the Staphylococcus aureus (SA), Pseudomonas aeruginosa (PA), and Klebsiella pneumonia $(\mathrm{KP})$ 
tools and devices, food processing machines and so on to prevent the infection related to the use of such components.

The nonlinear regression technique is capable to fit the results of the bacterial adhesion test using contact angle, nanoscale roughness, and microscale roughness as independent variables. It has been found that one model, with different coefficients, is suitable for the gram negative coccobacillui bacteria (Klebsiella pneumonia), gram positive cocci bacteria (Staphylococcus aureus), and the gram negative bacilli bacteria (Pseudomonas aeruginosa). Thus, employment this technique, with the aid of ternary contour graphs, to study the adhesion of different bacterial species to different surfaces may help in prediction and understanding the effect of the multi scale surface features on the resistance to bacterial adhesion.

\section{References}

1. An YH, Friedman RJ. Concise review of mechanisms of bacterial adhesion to biomaterial surfaces. Journal of Biomedical Materials Research. 1998;43(3):338-348.

2. Xing SF, Sun XF, Taylor AA, Walker SL, Wang YF, Wang SG. D-amino acids inhibit initial bacterial adhesion: thermodynamic evidence. Biotechnology and Bioengineering. 2015;112(4):696704.

3. Guégan C, Garderes J, Le Pennec G, Gaillard F, Fay F, Linossier I, et al. Alteration of bacterial adhesion induced by the substrate stiffness. Colloids Surfaces B: Biointerfaces. 2014;114:193-200. DOI: http://dx.doi.org/10.1016/j.colsurfb.2013.10.010

4. Chaw KC, Manimaran M, Tay FE. Role of Silver Ions in Destabilization of Intermolecular Adhesion Forces Measured by Atomic Force Microscopy in Staphylococcus epidermidis Biofilms. Antimicrobial Agents and Chemotherapy. 2005;49(12):48534859 .

5. Furno F, Morley KS, Wong B, Sharp BL, Arnold PL, Howdle SM, et al. Silver nanoparticles and polymeric medical devices: A new approach to prevention of infection? Journal of Antimicrobial Chemotherapy. 2004;54(6):1019-1024.

6. Sharmila G, Haries S, Farzana Fathima M, Geetha S, Manoj Kumar N, Muthukumaran C. Enhanced catalytic and antibacterial activities of phytosynthesized palladium nanoparticles using Santalum album leaf extract. Powder Technology. 2017;320:2226. DOI: http://dx.doi.org/10.1016/j.powtec.2017.07.026

7. Lorenzetti M, Dogša I, Stošicki T, Stopar D, Kalin M, Kobe $\mathrm{S}$, et al. The Influence of Surface Modification on Bacterial Adhesion to Titanium-Based Substrates. ACS Applied Materials \& Interfaces. 2015;7(3):1644-1651.

8. Hasan J, Jain S, Padmarajan R, Purighalla S, Sambandamurthy VK, Chatterjee K. Multi-scale surface topography to minimize adherence and viability of nosocomial drug-resistant bacteria. Materials \& Design. 2018;140:332-344. DOI: http://dx.doi. org/10.1016/j.matdes.2017.11.074

9. Zhang X, Wang L, Levänen E. Superhydrophobic surfaces for the reduction of bacterial adhesion. RSC Advances. 2013;3(30):12003. DOI: c3ra40497h
10. Gu H, Ren D. Materials and surface engineering to control bacterial adhesion and biofilm formation: A review of recent advances. Frontiers of Chemical Science and Engineering. 2014;8(1):20-33.

11. Rodrigues LR. Inhibition of Bacterial Adhesion on Medical Devices. In: Linke D, Goldman A, eds. Bacterial Adhesion. Dordrecht: Springer Netherlands; 2011. p. 351-367.

12. Gu J, Chen PZ, Seo BB, Jardin JM, Verma MS, Jahed Z, et al. Adhesion characteristics of Staphylococcus aureus bacterial cells on funnel-shaped palladium-cobalt alloy nanostructures. Journal of Experimental Nanoscience. 2016;11(7):480-489. DOI: http://dx.doi.org/10.1080/17458080.2015.1083126

13. Singh A, Ahmed A, Prasad KN, Khanduja S, Singh SK, Srivastava $\mathrm{JK}$, et al. Antibiofilm and membrane-damaging potential of cuprous oxide nanoparticles against Staphylococcus aureus with reduced susceptibility to vancomycin. Antimicrobial Agents and Chemotherapy. 2015;59(11):6882-6890.

14. Han A, Tsoi JKH, Rodrigues FP, Leprince JG, Palin WM. Bacterial adhesion mechanisms on dental implant surfaces and the influencing factors. International Journal of Adhesion and Adhesives. 2016;69:58-71. DOI: http://dx.doi.org/10.1016/j. ijadhadh.2016.03.022

15. Torres AG, Jeter C, Langley W, Matthysse AG. Differential Binding of Escherichia coli O157:H7 to alfalfa, human epithelial cells, and plastic is mediated by a variety of surface structures. Applied and Environmental Microbiology. 2005;71(12):80088015 .

16. Li B, Logan BE. Bacterial adhesion to glass and metal-oxide surfaces. Colloids and Surfaces B: Biointerfaces. 2004;36(2):8190 .

17. Razatos A, Ong YL, Sharma MM, Georgiou G. Molecular determinants of bacterial adhesion monitored by atomic force microscopy. Proceedings of the National Academy of Sciences of the United States of America. 1998;95(19):11059-11064.

18. Donlan RM. Biofilms: Microbial life on surfaces. Emerging Infectious Diseases. 2002;8(9):881-890.

19. Puckett SD, Taylor E, Raimondo T, Webster TJ. The relationship between the nanostructure of titanium surfaces and bacterial attachment. Biomaterials. 2010;31(4):706-713. DOI: http:// dx.doi.org/10.1016/j.biomaterials.2009.09.081

20. Giordano C, Saino E, Rimondini L, Pedeferri MP, Visai L, Cigada A, et al. Electrochemically induced anatase inhibits bacterial colonization on Titanium Grade 2 and Ti6A14V alloy for dental and orthopedic devices. Colloids and Surfaces B: Biointerfaces. 2011;88(2):648-655. DOI: http://dx.doi. org/10.1016/j.colsurfb.2011.07.054

21. He Z, Cai Q, Fang H, Situ G, Qiu J, Song S, et al. Photocatalytic activity of $\mathrm{TiO} 2$ containing anatase nanoparticles and rutile nanoflower structure consisting of nanorods. Journal of Environmental Sciences. 2013;25(12):2460-2468. DOI: http:// dx.doi.org/10.1016/S1001-0742(12)60318-0

22. Jiang W, Mashayekhi H, Xing B. Bacterial toxicity comparison between nano- and micro-scaled oxide particles. Environmental Pollution. 2009;157(5):1619-1625. DOI: http://dx.doi. org/10.1016/j.envpol.2008.12.025 
23. Pavithra D, Doble M. Biofilm formation, bacterial adhesion and host response on polymeric implants -- Issues and prevention. Biomedical Materials. 2008;3(3):034003.

24. Crosby AJ, Lee JY. Polymer Nanocomposites: The "Nano" Effect on Mechanical Properties. Polymer Reviews. 2007;47(2):217229.

25. Al-Rubiae MS. Polymer- Nanoparticles Composites for the Reduction of the Bacterial Adherence to Surfaces. Iraqi Journal of Biotechnology. 2016;15(3):17-24.

26. Wassmann T, Kreis S, Behr M, Buergers R. The influence of surface texture and wettability on initial bacterial adhesion on titanium and zirconium oxide dental implants. International Journal of Implant Dentistry. 2017;3(1):32. DOI: 10.1186/ s40729-017-0093-3

27. Habash M, Reid G. Microbial biofilms: their development and significance for medical device-related infections. Journal of Clinical Pharmacology. 1999;39(9):887-898.

28. Cheng G, Zhang Z, Chen S, Bryers JD, Jiang S. Inhibition of bacterial adhesion and biofilm formation on zwitterionic surfaces. Biomaterials. 2007;28(29):4192-4199.

29. Speranza G, Gottardi G, Pederzolli C, Lunelli L, Canteri R, Pasquardini L, et al. Role of chemical interactions in bacterial adhesion to polymer surfaces. Biomaterials. 2004;25(11):20292037.

30. Song F, Koo H, Ren D. Effects of Material Properties on Bacterial Adhesion and Biofilm Formation. Journal of Dental Research. 2015;94(8):1027-1034.

31. Habimana O, Semião AJC, Casey E. The role of cell-surface interactions in bacterial initial adhesion and consequent biofilm formation on nanofiltration/reverse osmosis membranes. Journal of Membrane Science. 2014;454:82-96. DOI: 10.1016/j. memsci.2013.11.043

32. Quirynen M, Marechal M, Busscher H, Weerkamp A, Darius, PL van Steenberghe D. The influence of surface free energy and surface roughness on early plaque formation. An in vivo study in man. Journal of Clinical Periodontology. 1990;17:138-144.

33. Teughels W, Van Assche N, Sliepen I, Quirynen M. Effect of Material Characteristics and/or Surface Topography on Biofilm Development. Clinical Oral Implants Research. 2006;17 Suppl 2:68-81.

34. Tanner J, Robinson C, Söderling E, Vallittu P. Early plaque formation on fibre-reinforced composites in vivo. Clinical Oral Investigations. 2005;9(3):154-160.

35. Rochford ETJ, Poulsson AHC, Salavarrieta Varela J, Lezuo P, Richards RG, Moriarty TF. Bacterial adhesion to orthopaedic implant materials and a novel oxygen plasma modified PEEK surface. Colloids and Surfaces B: Biointerfaces. 2014;113:213222. DOI: http://dx.doi.org/10.1016/j.colsurfb.2013.09.012

36. Al-Hydary IAD. Preparation and characterization of phase-pure anatase nanoparticles. The Iraqi Journal for Mechanical and Materials Engineering. 2014;14(1):98-106.

37. Chawla KK. Composite Materials. New York: Springer; 2012. DOI: $10.1007 / 978-0-387-74365-3$
38. Polli H, Pontes LAM, Araujo AS, Barros JMF, Fernandes VJ Jr. Degradation behavior and kinetic study of ABS polymer. Journal of Thermal Analysis and Calorimetry. 2009;95(1):131-134.

39. Farsani RE, Raissi S, Shokuhfar A, Sedghi A. FT-IR Study of Stabilized PAN Fibers for Fabrication of Carbon Fibers. International Journal of Mechanical and Mechatronics Engineering. 2009;3(2):161-164.

40. Qi R, Chen Z, Zhou C. Solvothermal preparation of maleic anhydride grafted onto acrylonitrile-butadiene-styrene terpolymer (ABS). Polymer. 2005;46(12):4098-4104.

41. Busani T, Devine RAB. Dielectric and infrared properties of $\mathrm{TiO}_{2}$ films containing anatase and rutile. Semiconductor Science and Technology. 2005;20(8):870.

42. Nakamoto K. Infrared and Raman Spectra of Inorganic and Coordination Compounds: Part A: Theory and Applications in Inorganic Chemistry. Hoboken: Wiley; 2009. 432 p.

43. Lerebour G, Cupferman S, Bellon-Fontaine MN. Adhesion of Staphylococcus aureus and Staphylococcus epidermidis to the Episkin reconstructed epidermis model and to an inert 304 stainless steel substrate. Journal of Applied Microbiology. 2004;97(1):7-16.

44. Al-Tahhan RAR. Cell surface hydrophobicity of Pseudomonas aeruginosa: Effects of monorhamnolipid and substrate on fatty acid and lipopolysaccharide content. [PhD Dissertation]. Tucson: University of Arizona; 1998.

45. Belaabed R, Elabed S, Addaou A, Laajab A, Rodríguez MA, Lahsini A. Synthesis of LTA zeolite for bacterial adhesion. Boletín de la Sociedad Española de Cerámica y Vidrio. 2016;55(4):152-158. DOI: http://dx.doi.org/10.1016/j. bsecv.2016.05.001

46. Camprubí S, Merino S, Benedí J, Williams P, Tomás JM. Physicochemical surface properties of Klebsiella pneumoniae. Current Microbiology. 1992;24(1):31-33.

47. Truong VK, Lapovok R, Estrin YS, Rundell S, Wang JY, Fluke CJ, et al. The influence of nano-scale surface roughness on bacterial adhesion to ultrafine-grained titanium. Biomaterials. 2010;31(13):3674-3683. DOI: http://dx.doi. org/10.1016/j.biomaterials.2010.01.071

48. Kathiresan S, Mohan B. In-vitro bacterial adhesion study on stainless steel 316L subjected to magneto rheological abrasive flow finishing. Biomedical Research. 2017;28(7):3169-3175.

49. Nejadnik MR, van der Mei HC, Norde W, Busscher HJ. Bacterial adhesion and growth on a polymer brush-coating. Biomaterials. 2008;29(30):4117-4121.

50. Barrett SP. Bacterial adhesion to intravenous cannulae: Influence of implantation in the rabbit and of enzyme treatments. Epidemiology and Infection. 1988;100(1):91100 .

51. Ahearn DG, Grace DT, Jennings MJ, Borazjani RN, Boles $\mathrm{KJ}$, Rose LJ, et al. Effects of hydrogel/silver coatings on in vitro adhesion to catheters of bacteria associated with urinary tract infections. Current Microbiology. 2000;41(2):120-125. 